\title{
Integrating neighbor clustering, coexpression clustering and subsystems analysis to define dynamic changes in regulatory networks associated with group A streptococcal sociomicrobiology and niche adaptation
}

\author{
Ramy K Aziz ${ }^{1,2 *}$, Bruce J Aronow ${ }^{3}$, William L Taylor ${ }^{4}$, Sarah L Rowe ${ }^{2,4}$, Rita Kansal ${ }^{2,5}$, Mark J Walker ${ }^{6}$, Malak Kotb ${ }^{2,5,6}$
}

From UT-ORNL-KBRIN Bioinformatics Summit 2010

Cadiz, KY, USA. 19-21 March 2010

\section{Background}

Bacterial colonies often consist of heterogeneous communities rather than genetically identical cells with harmonized gene expression profiles[1]. Dramatic changes, such as the onset of infection, may perturb a colony's sociomicrobiology leading a minor subpopulation with a mutant phenotype to prevail in the host; however, capturing such transitions in real time is difficult. While differential microarray analysis has become a method of choice for comparing the transcriptomes of bacterial subpopulations, current microarray analysis tools are more optimized to the study of eukaryotic organisms.

Here, we set out to develop a systems biology model for studying the transcriptional reprogramming underlying the transition of M1T1 group A streptococci[2] from a virulent to a hypervirulent phenotype [3-5]. In addition, we aimed at integrating and optimizing microarray analysis strategies to better understand bacterial regulatory networks.

\section{Materials and methods}

Using a murine subcutaneous chamber model developed in our laboratory[6], we sampled the bacteria before and $24 \mathrm{~h}$ after infection, and we compared the transcriptomes of wild type (WT) and animal-passaged (AP) bacteria in vitro and in vivo (Figure 1). To make biologically relevant discoveries without compromising the statistical

* Correspondence: ramy.aziz@salmonella.org

${ }^{1}$ Department of Microbiology and Immunology, Faculty of Pharmacy, Cairo University, Cairo, Egypt

\section{Design of Comparative Microarray Experiments}

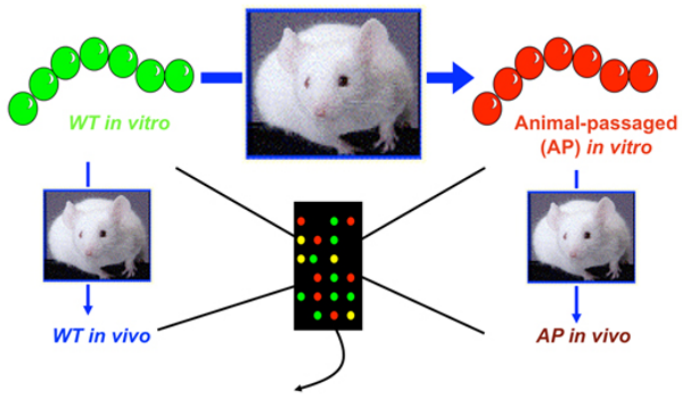

Compare all vs, all using oligomeric microarrays. Biological triplicates, with dye swaps, were run for each condition ( $4 \times 3 \times 2=24$ arrays).

Figure 1 Outline of the design of microarray experiments.

robustness of microarray analysis, we combined multiple analysis strategies, including coexpression clustering, neighbor clustering[7], and subsystems analysis[8]. Finally, we visually inspected all computer-generated data to filter out any artifacts or errors.

\section{Results and conclusion}

The integration of these methods revealed extensive transcriptional alterations of pathoadaptive and metabolic gene sets associated with invasion, immune evasion, and metabolic reprogramming. Comparing genomic subsystems involved in in vivo adaptation with those affected by animal-passage demonstrates that the WT bacteria struggled to adapt to the host environment 
by altering several virulence and metabolic modules that made their phenotype more similar to the mutant AP phenotype; still, WT bacteria failed to survive while the AP population thrived mainly because of a mutation in the gene encoding their global environmental sensor, CovS. We suggest that the transcriptional reprogramming of the WT bacteria was not sufficient for their adaptation to the host environment and that niche adaptation was only achieved by the selection/expansion of covS mutants.

This model allowed us to capture transcriptional snapshots of both survivor and extinct subpopulations in vivo and provided a proof of principle that in vivo transcriptomics of extinct microbial populations offers valuable clues to microbial niche adaptation. The integration of multiple microarray analysis tools and the customization of these tools to bacterial polycistronic transcripts demonstrate the importance taking biological relevance into consideration in high-throughput data analyses.

\section{Acknowledgments}

This work was partly supported by the Research and Development Office, Medical Research Service, Department of Veterans Affairs (Merit Award to MK), and by the National Health and Medical Research Council of Australia (project grant 459103 to MJW and MK).

A detailed study describing the experimental model and the

implementation of these methods in the analysis of group A streptococcal hypervirulence was recently published[9].

\section{Author details}

'Department of Microbiology and Immunology, Faculty of Pharmacy, Cairo University, Cairo, Egypt. ${ }^{2}$ The Veterans Affairs Medical Center, Memphis, TN 38104, USA. ${ }^{3}$ Biomedical Informatics, Children's Hospital Medical Center, Cincinnati, OH 45229, USA. ${ }^{4}$ University of Tennessee, Health Science Center, Memphis, TN 38163, USA. ${ }^{5}$ The Veterans Affairs Medical Center, Cincinnati, $\mathrm{OH} 45220$, USA. ${ }^{6}$ School of Biological Sciences, University of Wollongong, Wollongong, Australia.

Published: 23 July 2010

\section{References}

1. Parsek MR, Greenberg EP: Sociomicrobiology: the connections between quorum sensing and biofilms. Trends Microbiol 2005, 13:27-33.

2. Aziz RK, Kotb M: Rise and persistence of global M1T1 clone of Streptococcus pyogenes. Emerg Infect Dis 2008, 14:1511-1517.

3. Aziz RK, Pabst MJ, Jeng A, Kansal R, Low DE, Nizet V, Kotb M: Invasive M1T1 group A Streptococcus undergoes a phase-shift in vivo to prevent proteolytic degradation of multiple virulence factors by SpeB. Mol Microbiol 2004, 51:123-134.

4. Sumby P, Whitney AR, Graviss EA, DeLeo FR, Musser JM: Genome-wide analysis of group $A$ streptococci reveals a mutation that modulates global phenotype and disease specificity. PLoS Pathog 2006, 2:e5.

5. Walker MJ, Hollands A, Sanderson-Smith ML, Cole JN, Kirk JK, Henningham A, McArthur JD, Dinkla K, Aziz RK, Kansal RG, et al: DNase Sda1 provides selection pressure for a switch to invasive group A streptococcal infection. Nat Med 2007, 13:981-985.

6. Kazmi SU, Kansal R, Aziz RK, Hooshdaran M, Norrby-Teglund A, Low DE, Halim AB, Kotb M: Reciprocal, temporal expression of SpeA and SpeB by invasive M1T1 group A streptococcal isolates in vivo. Infect Immun 2001, 69:4988-4995.
7. Ryan PA, Kirk BW, Euler CW, Schuch R, Fischetti VA: Novel algorithms reveal streptococcal transcriptomes and clues about undefined genes. PLoS Comput Biol 2007, 3:e132.

8. Overbeek R, Begley T, Butler RM, Choudhuri JV, Chuang HY, Cohoon M, de Crecy-Lagard V, Diaz N, Disz T, Edwards R, et al: The subsystems approach to genome annotation and its use in the project to annotate 1000 genomes. Nucleic Acids Res 2005, 33:5691-5702.

9. Aziz RK, Kansal R, Aronow BJ, Taylor WL, Rowe SL, Kubal M, Chhatwal GS, Walker MJ, Kotb M: Microevolution of group A streptococci in vivo: capturing regulatory networks engaged in sociomicrobiology, niche adaptation, and hypervirulence. PLOS ONE 2010, 5:e9798.

doi:10.1186/1471-2105-11-S4-P12

Cite this article as: Aziz et al:: Integrating neighbor clustering,

coexpression clustering and subsystems analysis to define dynamic changes in regulatory networks associated with group A streptococcal sociomicrobiology and niche adaptation. BMC Bioinformatics 201011 (Suppl 4):P12.

\section{Submit your next manuscript to BioMed Central and take full advantage of:}

- Convenient online submission

- Thorough peer review

- No space constraints or color figure charges

- Immediate publication on acceptance

- Inclusion in PubMed, CAS, Scopus and Google Scholar

- Research which is freely available for redistribution

Submit your manuscript at www.biomedcentral.com/submit 